\title{
Weight Change and Glycemic Control After Diagnosis of Type 2 Diabetes
}

\author{
Adrianne C. Feldstein, $M D, M S^{1,2,3}$, Gregory A. Nichols, $P h D^{7}$, David H. Smith, RPh, MHA, $P h D^{7}$, \\ A. Gabriela Rosales, $M S^{7}$, and Nancy Perrin, $P h D^{7}$ \\ ${ }^{1}$ Center for Health Research, Kaiser Permanente Northwest, Portland, OR, USA; ${ }^{2}$ Northwest Permanente, Portland, OR, USA; ${ }^{3}$ Center for Health \\ Research, Portland, OR, USA.
}

BACKGROUND: Limited community-based data describe weight change after diabetes diagnosis.

OBJECTIVE: To evaluate weight change patterns and associations in the 1st year after diabetes mellitus type 2 diagnosis.

DESIGN: Retrospective cohort study.

PARTICIPANTS: Patients aged 21-75 with diabetes mellitus type 2 diagnosed between 1 January 1997 and 31 December 2004, identified from electronic medical records in Kaiser Permanente Northwest, a health maintenance organization. Eligible patients met weight measurement criteria (a baseline and three additional weight measurements) and did not have a condition associated with unintentional weight change $(\mathrm{n}=4,135)$.

MEASUREMENTS: We estimated 12-month patient weight trajectories using growth curve analyses, grouped similar trajectories using cluster analysis, and compared characteristics among groups.

RESULTS: The four weight trajectory groups were "higher stable weight" (n=757; 18.3\%), "lower stable weight" ( $n=2,236 ; 54.1 \%)$, “weight gain" $(n=664$; $16.0 \%)$, and "weight loss" $(n=478 ; 11.6 \%)$. After adjustments, members of the weight-loss group were more likely than those in the weight-gain group to be older, female, take fewer medications, have had nutritionist visits, and have a lower mean $\mathrm{HbA}_{1 \mathrm{c}}$. Those in the weight-loss group were less likely to be in a race group at higher risk for obesity, have depression or dyslipidemia, or have taken $>30$ days of a sulfonylurea alone or with metformin.

CONCLUSIONS: A small-but-substantial group of patients had a mean weight trajectory that included a clinically significant weight loss. Weight-loss trajectories were strongly associated with better glycemic control when compared to weight gain. Patients with certain characteristics may need more support for weight loss.

This study was supported by grant no. R21 DK073546-02 (Weight in Secondary Prevention) from the National Institute of Diabetes and Digestive and Kidney Diseases

Received September 21, 2007

Revised February 26, 2008

Accepted April 22, 2008

Published online June 28, 2008
KEY WORDS: diabetes; mellitus type 2; weight change; weight gain; weight loss; glycemic control.

J Gen Intern Med 23(9):1339-45

DOI: $10.1007 / \mathrm{s} 11606-008-0681-2$

(C) Society of General Internal Medicine 2008

\section{INTRODUCTION}

Optimizing weight can improve outcomes for type 2 diabetes patients, especially those with hypertension and dyslipidemia; ${ }^{1}$ most $(85.2 \%)$ adults with diabetes are overweight or obese. ${ }^{2}$ Weight loss in the overweight and obese reduces blood pressure, improves glucose control and blood lipids, and likely reduces mortality in patients with diabetes. ${ }^{3,4}$

Most information on weight change comes from crosssectional findings in the general population or from research cohorts who have limited weight measurements. ${ }^{5-7}$ Less information is available from community settings that might reflect the commonly utilized strategies to manage weight in diabetes. Also, many observational studies of health outcomes from weight change have been plagued by confounding of low weight by disease burden and by the difficulty in separating intentional from unintentional weight loss. ${ }^{8,9}$

This study used data from electronic medical records to evaluate weight change and associated factors in the first year after diabetes diagnosis of otherwise healthy patients. In particular, we aimed to identify the extent to which weight loss is achieved and the associated patient or treatment factors that should be considered by practitioners in new-onset diabetes. The findings may assist in community application of weight-loss strategies.

\section{METHODS}

The study was approved by the study site's Institutional Review Board.

\section{Study Site and Data Sources}

The study was conducted at Kaiser Permanente Northwest (KPNW), a not-for-profit group-model health maintenance organization (HMO) in Oregon and Washington with about 485,000 members from urban and rural settings and 1,200 physicians and allied clinicians. KPNW has electronic medical records (since 1996), with databases linked through each member's unique health record number. The databases cap- 
ture over $95 \%$ of the medical care and pharmacy services members receive, ${ }^{10}$ including weight at most visits, height, smoking status, diagnoses, procedures, medications, and laboratory results.

A registry of members with diabetes is derived from data on drug dispensings, diagnoses, and laboratory results. The registry has been shown to be $99.5 \%$ specific, and sensitivity is estimated at $99 \% .{ }^{11}$ Registrants mirror the national population of persons with diagnosed diabetes. ${ }^{11}$ The KPNW clinical guideline for the care of diabetes was consistent with American Diabetes Association (ADA) guidelines ${ }^{1}$ during the study period. KPNW recommends lifestyle management for all diabetes patients, and a stepped-care approach to the use of medication for obtaining optimal glycemic and other risk factor control. Generally, newly diagnosed patients are referred to diabetes classes and about $75 \%$ attend. Fewer than $10 \%$ attend weight-loss classes. Visits to a nutritionist are covered if the patient is referred by a clinician. Weight-related health education classes are available for a fee.

\section{Study Design and Participants}

This retrospective cohort study evaluated the weight trajectories of type 2 diabetes patients between 1 January 1997 and 31 December 2005. We identified patients aged 21-75 with newly diagnosed diabetes from 1 January 1997-31 December 2004 with 12 months' continuous HMO membership pre- and post-diagnosis $(n=12,602)$. Diabetes was assigned for those with a diabetes registry entry date. A diagnosis was considered to be "new" if the patient had not met the qualifying criteria (inpatient or outpatient diagnosis, fasting plasma glucose $>125 \mathrm{mg} / \mathrm{dl}$, diabetes medication dispensed) in the 12 months prior to diabetes registry entry. The registry entry date served as the study index date.

We included only those who had a baseline weight measurement and at least three weight measurements in the 15 months after diagnosis; the final weight had to occur between 6 and 15 months post-index $(n=5,868)$. Of those excluded due to height and weight requirements, $15.9 \%$ were missing heights and $84.1 \%$ weights $(33.9 \%$ no baseline, followup: $10.9 \%$ none, $32.1 \%$ one, $7.2 \%$ two). Those excluded were younger ( 54.6 vs. $56.3 ; \mathrm{p}<0.001$ ) and more likely to be male (59.6\% vs. $46.9 \%$; $\mathrm{p}<0.001)$.

We excluded 1,150 patients with a severe illness or condition associated with unintentional weight change in the 12 months pre-period or during trajectory: $60.0 \%$ with cancer, $14.0 \%$ on home oxygen, $12.0 \%$ with a pregnancy, and $14.0 \%$ with any of the following: HIV, nutritional deficiency, amputation, bariatric surgery, dialysis, hospice, $\mathrm{BMI}<20$, or care facility with length of stay $>30$ days $(n=4,718)$. We limited the population to those with type 2 diabetes, excluding 583 with type 1 diabetes (final $\mathrm{n}=4,135$ ).

\section{Study Variables}

The primary outcome was weight in pounds. All available weight measurements (expected to be measured at all visits in indoor clothing without shoes) were included to create a 12month weight trajectory for each patient (see Statistical Analysis below). We defined the 12-month weight as the weight closest to 12 months that fell between 9 months and 15 months.
We evaluated demographic, medical condition, and medication use variables based upon their known or suspected association with weight or weight change. ${ }^{12-15}$ Demographic covariates included age at index date; gender; whether or not the individual was in a "race-risk" group, defined as membership in a racial group at higher risk for obesity (Black, Hispanic, Native American, and Pacific Islander, combined); and family income $<\$ 40,000$ per year. Race at the individual level was available in KPNW databases on $73 \%$ of patients; missing race data and family income were assigned using census tract block data that corresponded with each participant's mailing address.

We also included baseline body mass index (BMI) (weight in kilograms divided by height in meters squared), using the weight in the pre-period closest to the index date, and any height. BMI was stratified, and we determined the presence or absence of obesity (BMI >30). We assessed whether the patient was a current smoker using the pre-period record closest to the index date.

We determined for the pre-period the mean number of unique medications the patient was dispensed as a measure of disease burden ${ }^{16}$ and the presence or absence of certain diagnoses, using ICD-9 diagnosis codes (Appendix): depression, hypertension, dyslipidemia, cardiovascular disease (excluding congestive heart failure), microvascular disease, and several non-cardiovascular conditions that could interfere with activity [asthma, chronic obstructive pulmonary disease (COPD), and arthritis).

Patients were categorized into four mutually exclusive categories of interest according to their diabetes medication use during the 12-month weight trajectory measurement period: "sulfonylureas" (SU) for those who had been dispensed $>30$ days of sulfonylureas (but not metformin); "metformin" for those dispensed $>30$ days of metformin (but not sulfonylureas); "SU and metformin" for those dispensed >30 days of both; "no DM (diabetes) medication" for those who had under 30 days of use or were not dispensed any diabetes medications. We assessed the use of insulin (any) and other diabetes medications ( $>30$ days), the presence or absence of visit/s to a nutritionist, the number of visits to an endocrinologist and to primary care (internal medicine of family practice), and whether or not the patient quit smoking during the trajectory period based on any recorded documentation of "quitting" during the 12 months.

We assessed glycemic control among those who had at least one glycosylated hemoglobin $\left(\mathrm{HbA}_{\mathbf{1 c}}\right)$ measurement after the index date during the 12-month trajectory period. Over $90 \%$ $(3,741 / 4,135 ; 90.5 \%)$ had at least one measurement. We determined the mean $\mathrm{HbA}_{\mathbf{1 c}}$ based upon all available measures during the trajectory. We determined whether or not the mean $\mathrm{HbA}_{\mathbf{1 c}}$ was above goal $(>7 \%)$ and the mean $\mathrm{HbA}_{\mathbf{1 c}}$ stratum. For the $2,413(58.4 \%)$ who had an $\mathrm{HbA}_{\mathbf{1 c}}$ both in the 3-month window around diagnosis and at 12 months, we ascertained $\mathrm{HbA}_{\mathbf{1 c}}$ change.

\section{Statistical Analysis}

To analyze weight change over time, individual weight trajectories were estimated using growth curve analyses (also called multilevel modeling) with HLM 6.0. Time formed the first level of the model, with weight as the dependent variable. Linear and quadratic models were estimated to determine the best fit 


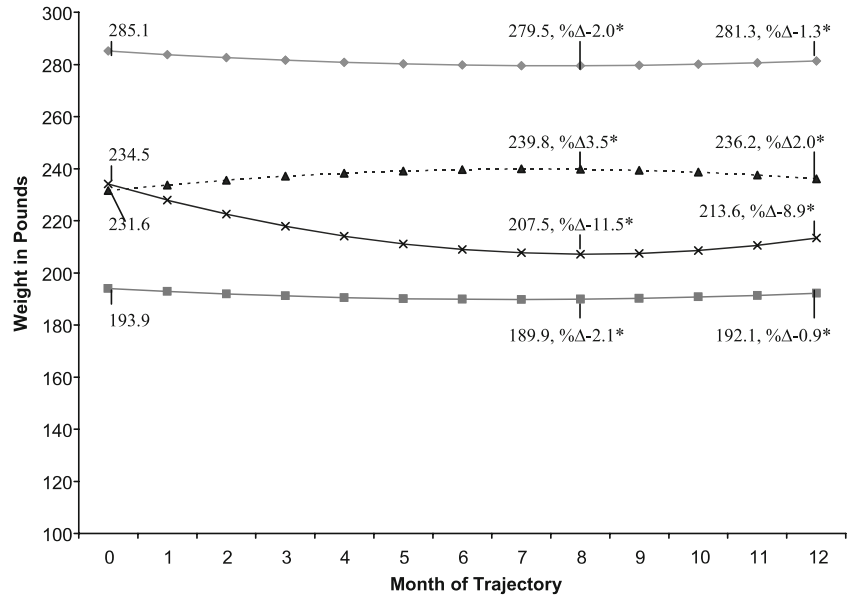

Figure 1. The four dominant weight-change trajectories in the first year after new-onset diabetes type 2.

Black diamonds $=$ higher stable weight, $\mathrm{n}=757$; gray square $=$ lower stable weight, $n=2,236$; black triangle $=$ weight gain, $n=664$; black small letter " $\mathrm{x}$ " weight loss, $\mathrm{n}=478$. $* \%$-Percentage change from baseline. All percentage changes (month 0 to month 8 and month 0 to month 12) are significantly different from zero (all p-values $<0.001$, based on Wilcoxon signed rank test) Equations: high stable: weight $=285.1-1.5$ month +0.1 month $^{2}$, lower stable: weight $=193.9-1.2$ month +0.09 month $^{2}$, weight gain: weight $=$ 231.6+2.3 month -0.2 month $^{2}$, weight loss: weight $=234.5-6.7$ month + 0.4 month $^{2}$.

to the data. The intercept and slope parameters that describe each person's weight trajectory were then entered into a hierarchical cluster analysis with Ward's Method in SPSS 15.0 to identify groups of patients with similar weight trajectory patterns. Once groups of individuals with similar weight trajectories were identified, analysis of variance (ANOVA) and chi-square tests were used to compare the groups. To better understand differences between those on a weight-loss trajectory and those on a weight-gain trajectory, multiple logistic regression was used, including age, gender, obesity, race, income, smoking (current; quit), number of medications, depression, dyslipidemia, SU, metformin, SU + metformin, nutrition visits, and $\mathrm{HbA}_{\mathbf{1 c}}$. We considered $\mathrm{p}<0.05$ to be statistically significant.

\section{RESULTS}

The figure reveals the four weight trajectory clusters. The "higher stable weight" group $(\mathrm{n}=757 ; 18.3 \%)$ had a small weight loss (5.6 lb; $2.0 \%$ loss at 8 months) followed by a regain. The "lower stable weight" group $(n=2,236 ; 54.1 \%)$ had a small weight loss ( $4.0 \mathrm{lb} ; 2.1 \%$ loss at 8 months) followed by a regain. The "weight-gain" group $(n=664 ; 16.0 \%)$ had a weight gain $(8.2 \mathrm{lb} ; 3.5 \%$ gain at 8 months) followed by a small loss. The "weight-loss" group $(n=478 ; 11.6 \%)$ had a clinically important $^{3,4}$ weight loss $(27.0 \mathrm{lb} ; 11.5 \%$ loss at 8 months $)$ followed by a small regain. All percentage changes were significant at $\mathrm{p}<0.001$ (Fig. 1).

Table 1 compares baseline characteristics among the four weight trajectory groups. The four groups were significantly different with respect to age, gender, baseline weight and BMI, race, income, smoking, number of medications, and diagnosed depression, hypertension, dyslipidemia, and combined asthma/COPD/arthritis. Note the significantly different BMI distribution between the weight-gain and weight-loss groups, even though they had similar mean baseline weights.

Table 1. Baseline Characteristics of New-onset DM Type 2 Patients in Four Dominant First-year Weight Trajectories

\begin{tabular}{|c|c|c|c|c|c|}
\hline \multirow[t]{2}{*}{ Characteristic } & \multicolumn{5}{|l|}{ Weight-change pattern } \\
\hline & Higher stable weight & Lower stable weight & Weight gain & Weight loss & P value* \\
\hline $\mathrm{N}$ & 757 & 2,236 & 664 & 478 & \\
\hline Age, mean $\pm \mathrm{SD}$ & $52.7 \pm 9.7$ & $57.7 \pm 10.2$ & $53.9 \pm 9.7$ & $55.9 \pm 9.7$ & $<0.001 \dagger$ \\
\hline Gender ( $\%$ female) & $330(43.6)$ & $1316(58.9)$ & $258(38.9)$ & $251(52.5)$ & $<0.001 \dagger$ \\
\hline Baseline weight lbs, mean $\pm \mathrm{SD}$ & $285.4 \pm 43.1$ & $194.2 \pm 33.8$ & $231.2 \pm 39.4$ & $235.8 \pm 45.9$ & $<0.001$ \\
\hline Baseline $\mathrm{BMI} \ddagger$ & & & & & $<0.001 \dagger$ \\
\hline $\mathrm{BMI}<25$ & $0(0.0)$ & $171(7.6)$ & $11(1.7)$ & $7(1.4)$ & \\
\hline $25 \leq \mathrm{BMI}<30$ & $8(1.0)$ & $666(29.8)$ & $119(17.9)$ & 54 (11.3) & \\
\hline $30 \leq \mathrm{BMI}<40$ & 267 (35.3) & $1213(54.3)$ & 378 (56.9) & 267 (55.9) & \\
\hline $\mathrm{BMI} \geq 40$ & $482(63.7)$ & $186(8.3)$ & $156(23.5)$ & $150(31.4)$ & \\
\hline Race-risk, n (\%)§ & $31(4.1)$ & $151(6.8)$ & $46(6.9)$ & $18(3.8)$ & $0.006 \dagger$ \\
\hline Income ( $\%$ family income $<\$ 40 K$ ) & $151(20.0)$ & $407(18.2)$ & $136(20.5)$ & $65(13.6)$ & $0.02 \dagger$ \\
\hline Smoking (current), n (\%) & $134(17.7)$ & $425(19.0)$ & $162(24.4)$ & $74(15.5)$ & $<0.001 \dagger$ \\
\hline Medications, mean $\pm \mathrm{SD}$ & $8.3 \pm 5.5$ & $7.8 \pm 5.5$ & $8.4 \pm 6.1$ & $7.4 \pm 5.3$ & $0.005 \dagger$ \\
\hline Depression, n (\%) & $121(16.0)$ & $285(12.8)$ & $106(16.0)$ & $56(11.7)$ & $0.02 \dagger$ \\
\hline Hypertension, n (\%) & 428 (56.5) & $1067(47.7)$ & 307 (46.2) & $249(52.1)$ & $<0.001$ \\
\hline Dyslipidemia, n (\%) & $165(21.8)$ & $606(27.1)$ & $153(23.0)$ & 85 (17.8) & $<0.001 \dagger$ \\
\hline CVD (excluding CHF) $\|, \mathrm{n}(\%)$ & 78 (10.3) & $270(12.1)$ & $80(12.1)$ & $50(10.5)$ & 0.48 \\
\hline Microvascular disease, n (\%) & $69(9.1)$ & $155(6.9)$ & $38(5.7)$ & $30(6.3)$ & 0.07 \\
\hline Asthma/COPD/Arthritis, II n (\%) & 219 (28.9) & $548(24.5)$ & $182(27.4)$ & $108(22.6)$ & 0.03 \\
\hline
\end{tabular}

*Comparison across all four groups (group patterns determined through cluster analysis)

$\dagger$ Comparison of weight-gain compared to weight-loss groups also significant at $p<0.05$

$\doteqdot B M I=$ body mass index

$\S$ Defined as Black/Hispanic/American Indian/Pacific Islander

$\| C V D=$ cardiovascular disease, $C H F=$ congestive heart failure

IICombined non-cardiovascular diagnoses that may interfere with activity; chronic obstructive pulmonary disease (COPD) 
Table 2. Diabetes Medication and other Factors During Trajectory Associated with Weight-change Patterns

\begin{tabular}{|c|c|c|c|c|c|}
\hline \multirow[t]{2}{*}{ Characteristic } & \multicolumn{5}{|l|}{ Weight-change pattern } \\
\hline & Higher stable weight & Lower stable weight & Weight gain & Weight loss & P value* \\
\hline $\mathrm{N}$ & 757 & 2,236 & 664 & 478 & \\
\hline \multicolumn{6}{|l|}{ DM medication class\# } \\
\hline Sulfonylureas (SU) $\ddagger$, N (\%) & $214(28.3)$ & 589 (26.3) & $260(39.2)$ & 95 (19.9) & $<0.001 \S$ \\
\hline Metformin $\|, \mathrm{N}(\%)$ & $107(14.1)$ & $287(12.8)$ & $51(7.7)$ & $92(19.3)$ & $<0.001 \S$ \\
\hline SU and metformin $I$, N (\%) & $64(8.5)$ & $161(7.2)$ & $110(16.6)$ & $19(4.0)$ & $<0.001 \S$ \\
\hline Insulin $\dagger, \mathrm{N}(\%)$ & $6(0.8)$ & $25(1.1)$ & $15(2.3)$ & $5(1.1)$ & 0.062 \\
\hline Thiazolidinedione\#, N (\%) & $1(0.13)$ & $1(0.04)$ & $1(0.15)$ & 0 & 0.679 \\
\hline Acarbose\#, N (\%) & $2(0.26)$ & $5(0.22)$ & $3(0.45)$ & 0 & 0.490 \\
\hline Repaglinide\#, N (\%) & 0 & $1(0.04)$ & 0 & 0 & 0.838 \\
\hline No DM medication, n (\%) & 370 (48.9) & $1,191(53.3)$ & 241 (36.3) & 270 (56.5) & $<0.001 \S$ \\
\hline Nutrition visits (any), n (\%) & $132(17.4)$ & $432(19.3)$ & $111(16.7)$ & $110(23.0)$ & $0.04 \S$ \\
\hline Endocrinology visits, mean $\pm \mathrm{SD}$ & $0.04 \pm 0.4$ & $0.05 \pm 0.4$ & $0.06 \pm 0.4$ & $0.05 \pm 0.4$ & 0.692 \\
\hline Primary care visits mean \pm SD & $4.2 \pm 3.8$ & $4.1 \pm 3.7$ & $5.0 \pm 4.4$ & $3.7 \pm 3.5$ & $<0.001 \S$ \\
\hline Quit smoking, n (\%) & $24(3.2)$ & $46(2.1)$ & $32(4.8)$ & $9(1.9)$ & $0.001 \S$ \\
\hline
\end{tabular}

*Comparison across all four groups

$\dagger$ Any use of insulin during year 1

$\$$ Received $>30$ days of $S U$ during year 1

$\S$ Comparison of weight-gain compared to weight-loss groups also significant at $p<0.05$

$\|$ Received $>30$ days of metformin during year 1

IIReceived $>30$ days of $\mathrm{SU}$ and metformin during year 1

\#Received $>30$ days of thiazolidinedione (TZDs), or acarbose, or repaglinide during year 1

Table 2 compares diabetes medications and other factors among the four weight trajectory groups. The most striking differences were between the weight-gain group and the weight-loss group. The weight-gain group had higher frequencies than the weight-loss group of taking an SU alone $(39.2 \%$ vs. $19.9 \%$, p-value $<0.001$ ) or in combination with metformin ( $16.6 \%$ vs. $4.0 \%$, p-value $<0.001$ ). The weight-loss group had higher frequencies than the weight-gain group of taking metformin without an SU $(19.3 \%$ vs. $7.7 \%$, p-value $<0.001)$ or no diabetes medication $(56.5 \%$ vs. $36.3 \%$, p-value $<0.001)$.
Few patients were using other diabetes medications. The weight-loss group had higher frequencies of one or more visits to a nutritionist $(23.0 \%$ vs. $16.7 \%$, p-value $=0.008)$, but a lower mean number of visits to primary care. The weight loss group had lower frequencies than the weight-gain group of having quit smoking during the trajectory period $(1.9 \%$ vs. $4.8 \%$, p-value $=0.009$ )

Table 3 compares glycemic control among the four weight trajectory groups. Compared with the other groups and especially the weight-gain group, being in the weight-loss

Table 3. Diabetes Control Measures During Trajectory Associated with Weight-change Patterns

\begin{tabular}{|c|c|c|c|c|c|}
\hline \multirow[t]{2}{*}{ Characteristic } & \multicolumn{5}{|l|}{ Weight-change pattern } \\
\hline & Higher stable weight & Lower stable weight & Weight gain & Weight loss & P value* \\
\hline $\mathrm{N}$ & 757 & 2,236 & 664 & 478 & \\
\hline $\begin{array}{l}\text { With } \mathrm{HbA}_{1 \mathrm{c}}^{\dagger} \\
\mathrm{N}(\%)\end{array}$ & $682(90.1)$ & $2,022(90.4)$ & $593(89.3)$ & 444 (92.9) & \\
\hline $\begin{array}{l}\text { Above-goal } \\
\text { mean } \mathrm{HbA}_{1 \mathrm{c}} \text { during year§, n (\%) }\end{array}$ & $294(43.1)$ & $810(40.1)$ & $330(55.7)$ & $109(24.6)$ & $<0.001 \|$ \\
\hline$\% \mathrm{HbA}_{1 \mathrm{c}}$ mean $\pm \mathrm{SD}$ & $7.1 \pm 1.2$ & $7.0 \pm 1.2$ & $7.5 \pm 1.5$ & $6.6 \pm 1.0$ & $<0.001 \|$ \\
\hline Median & 6.8 & 6.7 & 7.2 & 6.3 & \\
\hline IQR & $6.3,7.7$ & $6.2,7.5$ & $6.4,8.3$ & $5.9,6.9$ & \\
\hline Mean $\% \mathrm{HbA}_{1 \mathrm{c}}$ & & & & & $<0.001 \|$ \\
\hline$<7, \mathrm{n}(\%)$ & 388 (56.9) & $1,212(59.9)$ & 263 (44.3) & 335 (75.5) & \\
\hline $7-8, \mathrm{n}(\%)$ & $163(23.9)$ & $487(24.1)$ & $141(23.8)$ & $72(16.2)$ & \\
\hline $8-9$, n $(\%)$ & $77(11.3)$ & $194(9.6)$ & $94(15.9)$ & $25(5.6)$ & \\
\hline $9+, \mathrm{n}(\%)$ & $54(7.9)$ & $129(6.4)$ & $95(16.0)$ & $12(2.7)$ & \\
\hline With $\Delta \mathrm{HbA}_{1 \mathrm{c}} \neq, \mathrm{n}(\%)$ & $424(56.0)$ & $1323(59.2)$ & $370(55.7)$ & 296 (61.9) & \\
\hline$\Delta \mathrm{HbA}_{1 \mathrm{c}}$ mean $\pm \mathrm{SD}$ & $-1.2 \pm 2.1$ & $-1.5 \pm 2.2$ & $-1.9 \pm 2.5$ & $-2.1 \pm 2.0$ & $<0.001$ \\
\hline Median & -0.6 & -0.8 & -1.3 & -1.5 & \\
\hline IQRII & $-2.2,0.1$ & $-2.6,-0.1$ & $-3.6,-0.1$ & $-3.0,-0.7$ & \\
\hline
\end{tabular}

*Comparison across all four groups

$\dagger H b A_{1 c}=$ Hemoglobin A1c; includes those with one or more measures during 1-year trajectory

$\ddagger$ Change from baseline to end of year 1 ; includes those with measures of $\mathrm{HbA}_{1 \mathrm{c}}$ both in 3-month window around DM diagnosis and 12 months $\$$ All available measures are included

|| Comparison of weight-gain compared to weight-loss groups also significant at $p<0.05$

IIIQR = interquartile range 
group was associated with having a lower mean $\mathrm{HbA}_{\mathbf{1 c}}(6.6 \pm$ 1.0 in weight loss vs. $7.5 \pm 1.5$ in weight gain). The weight-loss group also had the highest percentage of patients who were below goal, i.e., had $\mathrm{HbA}_{1 \mathrm{c}}<7 \%$ (75.5\% in weight loss vs. $44.3 \%$ in weight gain). The weight-loss group had a more favorable distribution of $\mathrm{HbA}_{\mathbf{1 c}}$ results, including the lowest percentage of individuals who were poorly controlled, i.e., had $\% \mathrm{HbA}_{1 \mathbf{c}}$ of $9+(2.7 \%$ in weight loss vs. $16.0 \%$ in weight gain, $\mathrm{p}$ value $<0.001$ ) and the largest change in $\mathrm{HbA}_{\mathbf{1 c}}$.

The logistic regression model comparing the weight-loss group to the weight-gain group is presented in Table 4 . Each year of age increased the odds of being in the weight-loss group by a factor of 0.02 (OR 1.02; 95\% CI 1.00-1.03). Being a woman (OR 1.95; 95\% CI 1.44-2.64) or having nutritionist visits (OR 1.90; 95\% CI 1.33-2.72) nearly doubled the odds of being in the weight-loss group. Members of the weight-loss group were less likely than those in the weight-gain group to be in a race-risk weight group (OR 0.42; 95\% CI 0.21-0.83), to be taking a larger mean number of medications (OR 0.95; 95\% CI 0.93-0.98), to have depression (OR=0.57; 95\% CI 0.36-0.88) or dyslipidemia (OR 0.66 ; 95\% CI $0.46-0.94$ ), or to be taking an SU alone (OR=0.40; 95\% CI 0.29-0.55) or in combination with metformin (OR=0.27; 95\% CI 0.15-0.48). Finally, members of the weight-loss group were more likely than those in the weight-gain group to have a lower mean $\mathrm{HbA}_{\mathbf{1 c}}$ associated with the trajectory. Each percentage point of $\mathrm{HbA}_{1 \mathrm{c}}$ decreased the odds of being in the weight-loss group by a factor of.56 (OR 0.56; 95\% CI 0.49-0.65).

\section{DISCUSSION}

Contrary to commonly held beliefs, ${ }^{17}$ we found that a small but substantial group (11.6\%) of type 2 diabetes patients could achieve a mean weight loss of more than $10 \%$, an amount that has been thought to define an optimal clinically significant threshold. ${ }^{17}$ Importantly, after multivariable adjustment,

Table 4. Logistic Regression Model Comparing Weight-loss Group to Weight-gain Group

\begin{tabular}{|c|c|c|c|c|}
\hline \multirow{2}{*}{$\begin{array}{l}\text { Effect } \\
\text { Age* }^{*}\end{array}$} & \multirow{2}{*}{$\begin{array}{l}\text { Odds } \\
\text { ratio }\end{array}$} & \multicolumn{2}{|c|}{$\begin{array}{l}95 \% \text { Wald } \\
\text { confidence } \\
\text { limits }\end{array}$} & \multirow{2}{*}{$\begin{array}{c}\text { P value } \\
0.04\end{array}$} \\
\hline & & 1.00 & 1.03 & \\
\hline Gender (female)* & 1.95 & 1.44 & 2.64 & $<.0001$ \\
\hline $\mathrm{BMI} \geq 30^{*}$ & 1.34 & 0.89 & 2.02 & 0.16 \\
\hline Race-risk* & 0.42 & 0.21 & 0.83 & 0.01 \\
\hline Income (family income $<\$ 40 \mathrm{~K}$ )* & 0.72 & 0.49 & 1.06 & 0.10 \\
\hline Smoking (current)* & 0.87 & 0.59 & 1.29 & 0.49 \\
\hline Medications (mean number)* & 0.95 & 0.93 & 0.98 & $<0.001$ \\
\hline Depression* & 0.57 & 0.36 & 0.88 & 0.01 \\
\hline Dyslipidemia* & 0.66 & 0.46 & 0.94 & 0.02 \\
\hline Sulfonylureas (SU) $\dagger$ & 0.40 & 0.29 & 0.55 & $<0.001$ \\
\hline Metformin $\dagger$ & 1.51 & 0.36 & 6.34 & 0.58 \\
\hline $\mathrm{SU}+$ Metformin $\dagger$ & 0.27 & 0.15 & 0.48 & $<0.001$ \\
\hline Nutrition visits (any) $\dagger$ & 1.90 & 1.33 & 2.72 & $<0.001$ \\
\hline Quit smoking $\dagger$ & 0.67 & 0.26 & 1.72 & 0.40 \\
\hline $\mathrm{HbA}_{1 \mathrm{c}} \ddagger$ mean $\dagger$ & 0.56 & 0.49 & 0.65 & $<0.001$ \\
\hline
\end{tabular}

*These characteristics were assessed at baseline; BMI = body mass index $\dagger$ These characteristics were assessed during the trajectory $\ddagger H b A_{1 c}=$ Hemoglobin $A_{1 c}$ weight loss was strongly associated with better glycemic control when compared to weight gain. Because the microvascular and probable macrovascular benefits of good glycemic control are no longer in doubt, ${ }^{18}$ and because diabetes requires ongoing therapy intensification to achieve glycemic control, ${ }^{19}$ the importance of weight loss as a therapeutic approach cannot be overemphasized.

As is typical of most community practices, ${ }^{17}$ the study HMO does not direct as many resources to weight loss as it does to other aspects of diabetes care. Thus, community practitioners should be encouraged by the fact that some patients can achieve weight loss with minimal intervention. Because weight loss can reverse hyperglycemia and other cardiovascular disease risk factors, ${ }^{20,21}$ more effort is needed to manage weight trajectories in diabetes patients.

Several other findings may be useful for practitioners to consider when treating new-onset diabetes. Nutritionist visits nearly doubled the odds of being in the weight-loss group and should be seriously considered by practitioners. Men, younger individuals, African American, Native American, Pacific Islander, or Hispanic patients, and those who were sicker or who had depression or dyslipidemia were more likely to be in the weight-gain (vs. -loss) group. Such individuals may benefit from more intensive and culturally sensitive support for weight loss.

Most patients who initiated an anti-hyperglycemic agent received an SU. Currently, ADA guidelines ${ }^{1}$ recommend metformin as the first-line oral agent, in large part because it is at least weight neutral and may cause weight loss. Our data provide further support (consistent with prior research ${ }^{22-24}$ ) that the use of SUs in the 1st year after diabetes diagnosis should be avoided (when appropriate) if weight is a concern.

Patients who initially successfully lost weight appear to need additional support to maintain weight loss, because regain was the norm. Among all the weight trajectory groups except the weight-gain group, the weight change pattern included weight loss until about 8 months and then a weight regain. This suggests that the first 4-6 months after diabetes diagnosis may be critical for selecting and applying the optimal intensity of weight-loss treatments. These data support the urgent need for successful weight-loss maintenance programs, a current subject of active research. ${ }^{25}$

Several smaller observational studies using research cohorts evaluated a limited number of factors for their association with weight change in diabetes. ${ }^{5-7}$ In one study, 711 diabetes patients in a community-based practice participating in a diabetes clinical trial in Denmark experienced weight loss until about 5 months, whereupon weight stabilized or increased. ${ }^{5}$ Women were more likely than men to lose weight, and patients using insulin were more likely to gain weight. A study of 205 diabetes clinic attendees found a mean increase in body weight of $0.23 \mathrm{~kg}$ a year over 9 years. ${ }^{6}$ Another found that BMI trajectories among all adults depended predominantly on age and baseline BMI and that the rate of change in BMI was inversely proportional to baseline BMI. ${ }^{7}$ In our diabetes patient analyses, we did not find that the presence or absence of baseline obesity was significantly different between the weight-loss and weight-gain groups when controlling for confounders.

Our study has limitations. Only about half of diabetes patients met our height and weight criteria to be included. Our observational data were collected in the course of routine 
clinical care, representing varying time intervals; thus, weight and other measurements may not have been as precise as they would be during a clinical trial. $\mathrm{HbA}_{1 \mathrm{c}}$ data were incomplete. The study was strengthened, however, by our access to many measures on a large group of community-based new-onset diabetes patients.

The study was conducted at one HMO with relatively highquality diabetes care, ${ }^{11}$ so the findings may not be generalizable to other health-care settings or communities. The site did include patients from a large number of clinician practices in two states, however. Because patients were in the diabetes registry partially based on laboratory criteria, we cannot guarantee that all patients were aware they had diabetes, which might have increased their likelihood of attempting and being successful at losing weight.

We evaluated factors associated with weight trajectories. Such association does not establish causation. For example, in assessing glycemic control, although we were able to control for many factors that might distinguish those in the weightloss group from those in the weight-gain group, these groups may have been different in ways that we could not measure. For example, we tried to exclude participants with conditions that might lead to unintentional weight loss, but patients might have had undiagnosed or subclinical conditions.

Another concern is the lack of knowledge regarding temporal sequence: did those who gained weight do so because of higher $\mathrm{HbA}_{1 \mathrm{c}}$ (due to physiologic differences in their diabetes), or did they have poor $\mathrm{HbA}_{1 \mathrm{c}}$ control because of increased weight?

We did not evaluate many clinician and patient practices that may be important to weight change, such as clinician counseling and patient use of community weight-loss services, or the reasons and temporal changes for clinician selection of one therapeutic alternative versus another. Also, although we evaluated glycemic control, we did not evaluate the association between the various trajectories and other important outcomes, such as morbidity and mortality. These areas should be the focus of future research.

We found that a sizable group of new diabetes patients can achieve more favorable weight trajectories using common community practices, and we conclude that many more patients could benefit from weight loss and maintenance. Patients with certain characteristics may need more support for weight loss and maintenance, and health-care providers should be aware of and responsive to this subgroup. Future research should focus on improved implementation methods for diverse patients.

Acknowledgments: We would like to thank several individuals who assisted with the design and interpretation of the study and who were critical organizational advocates for the project: Victor
Stevens, PhD; Keith Bachman, MD; Harold Glauber, MD; Michael Herson, MD. We would also like to thank Martha Swain for editorial assistance and Debra Burch for administrative support.

Conflict of Interest: Dr. Feldstein has received research grants from Merck and Co., Inc., Sanofi-Aventis and Amgen. Dr. Nichols has received research grant support from GlaxoSmithKline Inc., BristolMyers Squibb, Sanofi-Aventis, Amgen, Merck \& Co., Inc., Pfizer Inc., and Eli Lilly \& Co. Dr. Smith has received research grant support from Sanofi-Aventis, Abbot, Amgen, and Genzyme.

Corresponding Author: Adrianne C. Feldstein, MD, MS; Center for Health Research, 3800 N Interstate Ave, Portland, OR 97227, USA (e-mail: Adrianne.C.Feldstein@kpchr.org).

\section{REFERENCES}

1. American Diabetes Association. American Diabetes Association Clinical Practice Recommendations. Diabetes Care. 2007;30(Suppl): 1S1-S103.

2. Centers for Disease Control and Prevention. Prevalence of overweight and obesity among adults with diagnosed diabetes-United States, 19881994 and 1999-2002. MMWR Morb Mortal Wkly Rep. 2004;53 (45): 1066-8

3. Gregg EW, Gerzoff RB, Thompson TJ, Williamson DF. Trying to lose weight, losing weight, and 9-year mortality in overweight U.S. adults with diabetes. Diabetes Care. 2004;27(3):657-62

4. Anderson JW, Kendall CW, Jenkins DJ. Importance of weight management in type 2 diabetes: review with meta-analysis of clinical studies. $J$ Am Coll Nutr. 2003;22(5):331-9.

5. de Fine ON, Andreasen AH, Siersma V, Richelsen B, Beck-Nielsen $\mathbf{H}$ Changes in patient weight and the impact of antidiabetic therapy during the first 5 years after diagnosis of diabetes mellitus. Diabetologia. 2006;49(9):2058-67.

6. Chaudhry ZW, Gannon MC, Nuttall FQ. Stability of body weight in type 2 diabetes. Diabetes Care. 2006;29(3):493-7.

7. Heo M, Faith MS, Mott JW, Gorman BS, Redden DT, Allison DB. Hierarchical linear models for the development of growth curves: an example with body mass index in overweight/obese adults. Stat Med. 2003;22(11):1911-42

8. French SA, Jeffery RW, Folsom AR, McGovern P, Williamson DF. Weight loss maintenance in young adulthood: prevalence and correlations with health behavior and disease in a population-based sample of women aged 55-69 years. Int $\mathrm{J}$ Obes Relat Metab Disord. 1996;20 (4):303-10.

9. Jeffreys M, McCarron P, Gunnell D, McEwen J, Smith GD. Body mass index in early and mid-adulthood, and subsequent mortality: a historical cohort study. Int J Obes Relat Metab Disord. 2003;27(11):1391-7.

10. Freeborn DK, Pope C. Promise and Performance in Managed Care: The Prepaid Group Practice Model. Baltimore, MD: Johns Hopkins University Press; 1994

11. Brown JB, Nichols GA, Glauber HS. Case-control study of 10 years of comprehensive diabetes care. West J Med. 2000;172(2):85-90.

12. Jeffery RW, McGuire MT, French SA. Prevalence and correlates of large weight gains and losses. Int J Obes Relat Metab Disord. 2002;26(7):969 72 .

13. Centers for Disease Control and Prevention-National Center for Health Statistics. Prevalence of overweight and obesity among adults: United 
States, 2003-2004. http://www cdc gov/nchs/products/pubs/pubd/ hestats/overweight/overwght_adult_03 htm [2007 Available from: URL: http://www.cdc.gov/nchs/products/pubs/pubd/hestats/overweight/ overwght_adult_03.htm.

14. Ambrosius WT, Newman SA, Pratt JH. Rates of change in measures of body size vary by ethnicity and gender. Ethn Dis. 2001;11(2):303-10.

15. French SA, Jeffery RW, Folsom AR, Williamson DF, Byers T. Relation of weight variability and intentionality of weight loss to disease history and health-related variables in a population-based sample of women aged 55-69 years. Am J Epidemiol. 1995;142(12):1306-14.

16. Schneeweiss S, Wang PS, Avorn J, Maclure M, Levin R, Glynn RJ. Consistency of performance ranking of comorbidity adjustment scores in Canadian and U.S. utilization data. J Gen Intern Med. 2004;19(5 Pt 1):444-50

17. Manson JE, Skerrett PJ, Greenland P, VanItallie TB. The escalating pandemics of obesity and sedentary lifestyle. A call to action for clinicians. Arch Intern Med. 2004;164(3):249-58.

18. UK Prospective Diabetes Study Group. Tight blood pressure control and risk of macrovascular and microvascular complications in type 2 diabetes: UKPDS 38. BMJ. 1998;317(7160):703-13.

19. UK Prospective Diabetes Study (UKPDS) Group. Intensive blood-glucose control with sulphonylureas or insulin compared with conventional treatment and risk of complications in patients with type 2 diabetes (UKPDS 33). Lancet. 1998;352(9131):837-53.

20. Ponce J, Haynes B, Paynter S, Fromm R, Lindsey B, Shafer A, et al. Effect of Lap-Band-induced weight loss on type 2 diabetes mellitus and hypertension. Obes Surg. 2004;14(10):1335-42.

21. Pi-Sunyer X, Blackburn G, Brancati FL, Bray GA, Bright R, Clark JM et al. Reduction in weight and cardiovascular disease risk factors in individuals with type 2 diabetes: one-year results of the look AHEAD trial. Diabetes Care. 2007;30(6):1374-83.

22. Nichols GA, Alexander CM, Girman CJ, Kamal-Bahl SJ, Brown JB. Contemporary analysis of secondary failure of successful sulfonylurea therapy. Endocr Pract. 2007;13(1):37-44.

23. Nichols GA, Alexander CM, Girman CJ, Kamal-Bahl SJ, Brown JB. Treatment escalation and rise in HbAlc following successful initial metformin therapy. Diabetes Care. 2006:29(3):504-9.

24. Nichols GA, Koo YH, Shah SN. Delay of insulin addition to ora combination therapy despite inadequate glycemic control: delay of insulin therapy. J Gen Intern Med. 2007;22(4):453-8.

25. Anderson JW, Konz EC, Frederich RC, Wood CL. Long-term weightloss maintenance: a meta-analysis of U.S. studies. Am J Clin Nutr. 2001;74:579-84

\section{APPENDIX}

Table 5. Appendix-ICD-9 Codes for Co-morbidities

\begin{tabular}{|c|c|}
\hline Co-morbidity & ICD-9 codes \\
\hline Arthritis & $\begin{array}{l}\text { 274.x, 696.0, 711.x, 712.x, 713.0, 714.x, } \\
\text { 715.x, 716.x, 720.x, 721.x }\end{array}$ \\
\hline Asthma & 493.x \\
\hline \multicolumn{2}{|l|}{ Cardiovascular disease } \\
\hline $\begin{array}{l}\text { Coronary artery } \\
\text { disease }\end{array}$ & $\begin{array}{l}410.90 A, 410.00-410.02,410.0-410.7 \\
410.10-410.12,410.20-410.22,410.30- \\
410.32,410.40-410.42,410.50-410.52, \\
410.60-410.62,410.70-410.72,410.80- \\
410.82,410.90-410.92,411.1,411.81, \\
411.89,413 . \mathrm{xx}, 414 . \mathrm{xx}, 36.10-36.17 \\
36.19,36.2,36.01,36.02,36.09,36.05, \\
\text { V45.81, V45.82 }\end{array}$ \\
\hline $\begin{array}{l}\text { Cardiac rhythm } \\
\text { disorders }\end{array}$ & $426 \cdot x-427 \cdot x$ \\
\hline $\begin{array}{l}\text { Cerebrovascular } \\
\text { disease }\end{array}$ & $\begin{array}{l}\text { 433.x-435.x, 437.0, 437.1, 438.x, 38.11, } \\
\text { 38.12, 00.61, 00.62, 00.64, 00.65 }\end{array}$ \\
\hline $\begin{array}{l}\text { Other cardiovascular } \\
\text { disease }\end{array}$ & 441.x, 442.x, 443.2, 444.1, 444.9,445.8x \\
\hline $\begin{array}{l}\text { Peripheral vascular } \\
\text { disease }\end{array}$ & 440.x, 443.81, 443.9, 444.2-444.8x, 445.0x \\
\hline COPD & 491.x, 492.x, 496.x \\
\hline Depression & $\begin{array}{l}296.2-296.80,296.82,296.89,296.9, \\
296.90,298.0,300.4,301.12,311 . x\end{array}$ \\
\hline Dyslipidemia & $272.0-272.4,272.9$ \\
\hline Hypertension & $\begin{array}{l}401 . x-404 . x, 405.01,405.09,405.11, \\
405.19,405.99,416 . x x, 437.2,440.1 \text {, } \\
796.2\end{array}$ \\
\hline \multicolumn{2}{|l|}{ Microvascular diseases } \\
\hline Nephropathy & $250.4,585.1-585.9,583.81,581.81$ \\
\hline Retinopathy & $\begin{array}{l}250.5,369.00-369.9,362.07,362.01- \\
362.07\end{array}$ \\
\hline Neuropathy & $\begin{array}{l}250.6,358.1,354.0-355.9,713.5,337.1, \\
357.2\end{array}$ \\
\hline Gastroparesis & $536.3,250.6$ \\
\hline
\end{tabular}

